\title{
Factors Influencing Turnover Intention of Physicians in Deprived Areas
}

\author{
Zahra Nikkhah-Farkhani ${ }^{1 *}{ }^{\circledR}$ Azadeh Soltani $^{2}{ }^{\circledR}$ \\ ${ }^{1}$ Business Management Department, University of Bojnord, Bojnord, Iran \\ ${ }^{2}$ Department of Computer Engineering, University of Bojnord, Bojnord, Iran
} *Corresponding Author: Zahra Nikkhah-Farkhani, Ph.D., Assistant Professor, Business Management Department,
University of Bojnord, Bojnord, Iran. Tel: +98-9156511743, Email: z.nikkhah@ub.ac.ir

Received October 29, 2020; Accepted March 2, 2021; Online Published March 20, 2021

\begin{abstract}
Background: The lack of specialist physicians is a major concern in developing countries, especially in deprived cities.

Objectives: This study aimed to identify the predictive variables of the turnover intention of physicians working in an undeveloped and deprived city in Iran.

Methods: Participants were 100 physicians working at North Khorasan University of Medical Sciences, Iran. The data were collected using a standard questionnaire of Turnover Intention, Interpersonal Conflict, Work-Family Conflict, Work Overload, and Organizational Support scales. We proposed a hybrid methodology to identify factors influencing turnover intention, which combines clustering and classification methods. RStudio 1.1, SPSS Clementine 12, and SPSS 22 programs were used for data analysis. After data clustering, we made a CART decision tree model for each cluster and used the variable importance feature of SPSS Clementine to discover the factors influencing turnover intention in each cluster.

Results: We found two significant clusters of physicians' turnover intention. In both clusters, interpersonal conflict (work ambiguity and work conflict) was the most important predictor of physician turnover intention, but physicians in the first cluster compared to the second had a higher turnover intention. In cluster 1, work overload, organizational support, and work-family conflict were respectively the predictors of physician turnover intention and in cluster 2, organizational support, work-family conflict, and final work overload were respectively the predictors of physician turnover intention.

Conclusion: Cultural differences and the resulting interpersonal conflicts are the most important predictors of physician turnover intention in deprived areas. Turnover intention predictions of physicians with a longer work experience are different from that of others, and human resource managers must implement appropriate strategies to keep physicians in the deprived areas.

Keywords: Turnover Intention, Work Ambiguity, Work Conflict, Organizational Support, Work-Family Conflict, Work Overload
\end{abstract}

\section{Background}

Turnover intention is the relative strength of an individual's desire to voluntarily withdraw from an organization. ${ }^{1}$ Understanding the factors that affect the turnover intention can help managers make better decisions about human resources (HR). ${ }^{2}$ Organizations that can understand the reasons and factors influencing employees' turnover intention will be able to implement effective policies and methods to maintain efficient HR before employees leave the organization. ${ }^{3}$ Physicians' turnover intention is very important, especially in Iran because currently, there is a shortage of specialist physicians per capita, and the distribution of specialist physicians is not optimal.

In some specialties, about $35 \%-40 \%$ of the physicians reside in Tehran, and the shortage of specialist physicians is one of the main concerns of health managers in deprived provinces such as North Khorasan. ${ }^{4}$ Research studies show that turnover intention can be a good predictor of turnover. $^{5}$

One of the most important predictors of employees' turnover intention is work-family conflict. ${ }^{6}$ Work-family conflict is defined as the incompatibility between work and family roles, which arises from inconsistent pressures on family and professional roles. In other words, a person is confronted with a role when he or she sees that playing two or more roles is always necessary, and these roles have incompatible expectations. ${ }^{7}$ Kinnunen and Mauno found that work-family conflict is different from familywork conflict. Work-family conflict occurs when the overall time allotted to the job and the pressure exerted on it disrupts family responsibilities, while family-work conflict is a form of conflict between the roles assigned to the family and the work time. ${ }^{8}$ The family and the pressures exerted by it interfere with the performance of job responsibilities. ${ }^{9}$ The literature shows that work-family conflict may lead to turnover intention and exacerbate the crisis of the shortage of specialist physicians in deprived areas. ${ }^{10}$ Based on research, in the case of physicians, both work-family and family-work conflicts occur. ${ }^{11}$ Doctors have a profession that deals directly with the patients' life.

Copyright (C) 2021 The Author(s). This is an open-access article distributed under the terms of the Creative Commons Attribution License (http:// creativecommons.org/licenses/by/4.0), which permits unrestricted use, distribution, and reproduction in any medium, provided the original work is properly cited. 
Any disruption or conflict in their work directly affects their family relationships, and the tensions resulting from family relationships affect their performance and thus the provision of services to patients. ${ }^{12}$ It is necessary to have positive communication between physicians and nurses in order to improve the quality of patient care, reduce conflicts between them, promote the efficiency as well as performance of the hospital, and provide higher-quality services to patients. ${ }^{13}$ Considering the importance of the role of HR in achieving the strategic goals of organizations, especially medical and hospital service centers that have a unique level of sensitivity, it is essential to pay attention to the factors affecting physicians' attitudes and behavioral variables.

Interpersonal conflict can be considered as the primary cause of work-family conflict. It involves two components: role conflict and role ambiguity, both of which can be effective in customer-centric and employee-centric work environments. ${ }^{14}$ According to Baruch and Barnett, when we play many roles, its consequence is a role conflict that leads to negative effects on the health of the mind and the body. ${ }^{15}$

Role conflicts occur when role-related demands directly interfere with one's ability to meet the demands of other roles. ${ }^{16}$ Sometimes there is no connection between the distribution of roles and the individual's abilities and expertise. Thus, distributing the roles based on people's abilities will reduce role conflicts.

Perception of organizational support is people's belief whose well-being and the level of participation in organizational success are important for their organization. ${ }^{17}$ The high level of perceived organizational support will promote employees' commitment to compensate for these benefits.

The best way to maximize servant employees is to treat employees in the way the organization wants them to treat the customers, which stems from the normative principle. ${ }^{18}$ Eisenberger et al introduced the term perceived organizational support and described employees' perceptions of the well-being provided by the organization. The organizational support perception is the criterion by which an employee evaluates an organization's emotional commitment to itself. ${ }^{19}$ Once employees realize that their organization supports them, they will reciprocate the support. Work overload refers to the large amount of work that is expected of a person and is defined as an indicator of the overall level of the mental or physical effort required to perform one or more tasks at a particular level of performance. Research studies show that junior physicians experience more work overload. In addition, the employment work overload will increase the workfamily conflict in this group of physicians. ${ }^{20}$

\section{Objectives}

Due to the negative effects of high employee turnover intention, HR managers should control it to maintain productivity. Studies have shown that the factors affecting turnover intention and its behavioral pattern in advantaged and disadvantaged areas are different from each other. ${ }^{21} \mathrm{On}$ the other hand, studies on turnover intention are focused on nurses and, little research has been done on physicians. This is while the lack of specialized medical services causes people to migrate to other cities to receive those services, which has many negative socio-economic consequences. However, the migration of people to receive nursing services is minimal. This increases the importance of examining the physician's turnover intention in disadvantaged areas. There are many reasons why turnover could occur in an organization. Some reasons are unavoidable, while some others such as work overload and organizational support can be controlled. Hence, the first step is to predict the turnover intention and then find the main factors affecting it. Decreasing the turnover intention is also essential for academic medical centers. Here, we aimed to investigate how we can predict the probability of the turnover intention of faculties in an academic medical center.

\section{Methods}

This cross-sectional study was conducted among the physicians that worked in North Khorasan University of Medical Sciences in Bojnourd, Iran. The participants were a total of 130 physicians. One hundred physicians were selected through random proportional sampling (the number of subpopulations in each department was selected in proportion to the number of population and then, random sampling techniques were applied to each subpopulation). This was conducted in the eight departments of the North Khorasan University of Medical Sciences.

Data collection was performed with standard questionnaires which included the Role Conflict and Ambiguity Scale ${ }^{21}$ with seven items, the Organizational Support Scale ${ }^{22}$ with three items, the Job Overload Scale ${ }^{23}$ with 15 items, the Work-Family Conflict ${ }^{24}$ with seven items and the Turnover Intention Scale $e^{25}$ with three items. The reliability of all questionnaires has been confirmed in the previous studies. ${ }^{26-29}$ For all of them, a five-point Likerttype scale from $1=$ strongly disagree to $5=$ strongly agree was used.

The reliability of the scores was evaluated by Cronbach's a. This coefficient was 0.68 for Role Conflict and Ambiguity Scale, 0.65 for Organizational Support Scale, 0.76 for the Job Overload Scale, 0.62 for Work-Family Conflict, 0.61 for Turnover Intention Scale, respectively. Studies show that Cronbach's alpha higher than 0.6 is acceptable. ${ }^{30}$ Therefore, since in this research, Cronbach's alpha for all questionnaires is higher than 0.6 , the reliability of the questionnaires is confirmed.

The validity method of "Lawshe"31 content was employed to assess the validity. Research objectives and operational definitions were presented to 14 experts in the field of organizational behavior, human resources, and medicine who were experts in the design of the questionnaire and were asked to answer each question based on the Likert 
three-part range of "necessary item", "useful item, but it is not necessary" and "item is not necessary". This formula was used to calculating CVR.

$\mathrm{CVR}=\left(\mathrm{n}_{\mathrm{e}}-\mathrm{n} / 2\right) /(\mathrm{n} / 2)$

In this formula, " $n_{e}$ " is the number of experts than chosen "necessary item" and " $n$ " is the total number of experts. The CVR was calculated more than 0.62 for each question that was acceptable (CVR $\geq 0.51)$.

We utilized a combination of clustering and classification methods, to find factors influencing turnover intention. RStudio 1.1, SPSS Clementine 12, and SPSS 22 programs were used for data analysis. Clustering is an unsupervised technique learning from unlabeled data. This method groups the set of instances into some groups, so that objects in each subset have similar characteristics. Hence, analyzing each cluster provides a more concise interpretation. Classification is a supervised method to predict the class label (turnover intention). In the first step, we removed turnover intention information from the data, thus the class variable had no impact on the clustering results. Then, we applied K-means to cluster data. After that, for each cluster, we made a decision-tree classification model (turnover intention information was used in this step). Finally, by analyzing these models, we identified factors influencing turnover intention. The algorithms are briefly discussed below:

- K-means clustering algorithm: K-means is one of the most basic and commonly used clustering algorithms. $\mathrm{k}$-means requires the user specify how many clusters should be generated. The algorithm works as follows:

1. It randomly selects $\mathrm{k}$ number of data samples as initial centers.

2. It computes the Euclidean distance of each observation from all the cluster centers.

3. All data points are assigned to the nearest cluster

4. Then it re-evaluates the cluster centers by considering the means of all data points in a cluster.

5. It repeats (steps two to four) until no new allocation occurs.32

- C\&R decision tree algorithm: Classification and Regression Tree (CART) is a discriminative machinelearning algorithm that uses a set of independent variables to split a set of samples into progressively smaller subgroups. It is a supervised method hence it constructs the model from a training dataset where the values of input and output are previously known. In each step, it finds the best splitter variable which clusters the parent node into two more homogenous children nodes (based on class label values). It constructs the tree in a top-down recursive divideand-conquer manner. The CART algorithm employs the Gini impurity index as the criterion to split a node.
Gini calculates the probability of a specific variable that is classified incorrectly when selected randomly. If a data set $\mathrm{T}$ contains examples from $\mathrm{n}$ classes, Gini(T) is defined as:

$\operatorname{gini}(T)=1-\sum_{j=1}^{n} p_{j}^{2}$

where $p j$ is the relative frequency of class $j$ in $T$. Gini (T) is minimized if the classes in $T$ are skewed. Hence, in each step, the attribute with the smallest gini split $(T)$ is chosen to split the node. ${ }^{33,34}$

\section{Results}

\subsection{Descriptive Statistics}

The study involved 100 physicians that worked at North Khorasan University of Medical Sciences. Forty-three percent of the respondents were female and $57 \%$ were men. Also, $32 \%$ of the respondents had $<5$ years of work experience, 65\% 5-10 years, and 3\% 10 years of work experience or more. Moreover, $48 \%$ of the respondents were $<35$ years, $36 \% 35-45$ years, $15 \% 45-55$ years, and $1 \%$ $>55$ years old.

\subsection{Clustering Analysis}

To make a more accurate prediction, we first clustered the samples into $\mathrm{K}$ groups, where each group aggregated the data with similar characteristics. We did not use the turnover intention for clustering. Then, we modeled each group and predicted the probability of turnover intention. We applied the K-means algorithm for clustering, which is one of the simplest and most popular clustering algorithms. Although K-means is a relatively efficient approach, we had to specify the number of clusters. Various strategies have been proposed to estimate the optimal number of clusters. Here, we employed multiple approaches to select the optimal $\mathrm{K}$. The first method used was the elbow approach, which runs $\mathrm{K}$-means on the dataset for a range of values for $\mathrm{K}$, and then for each $\mathrm{K}$, calculates the total within-cluster sum of squares (WSS). Then, it plots the curve of WSS according to the number of clusters K. If the plot looks like an arm, then the elbow on the arm is the optimal number of clusters $(\mathrm{K})$. The elbow plot illustrated in Figure 1 indicates that for our running dataset, the optimal number of clusters was three.

Another approach is the Calinski method which maximizes the $\mathrm{CH}(\mathrm{g})$ over the number of clusters $(\mathrm{g})$. $\mathrm{CH}(\mathrm{g})$ is calculated based on the between- and withincluster sum of squared errors. Figure 2 depicts the output of this method running in RStudio. As obvious in Figure 2, the optimal number of clusters according to the Calinski criterion is three. The third technique used for choosing the optimal number of clusters is a model-based method that maximizes the Bayesian information criterion (BIC). Figure 3 illustrates the results of this approach. It also confirms that the optimal number of clusters in our dataset is three.

After finding the optimal number of clusters, we used 


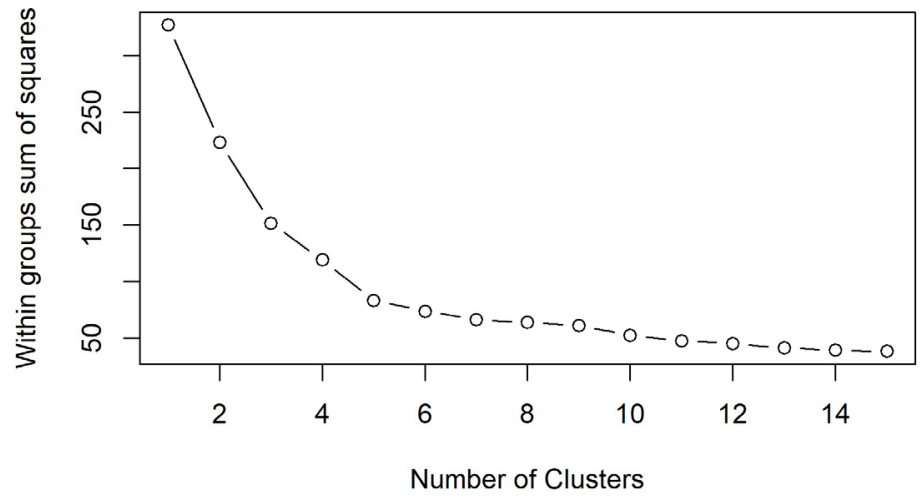

Figure 1. The Elbow Plot of the Running Dataset.

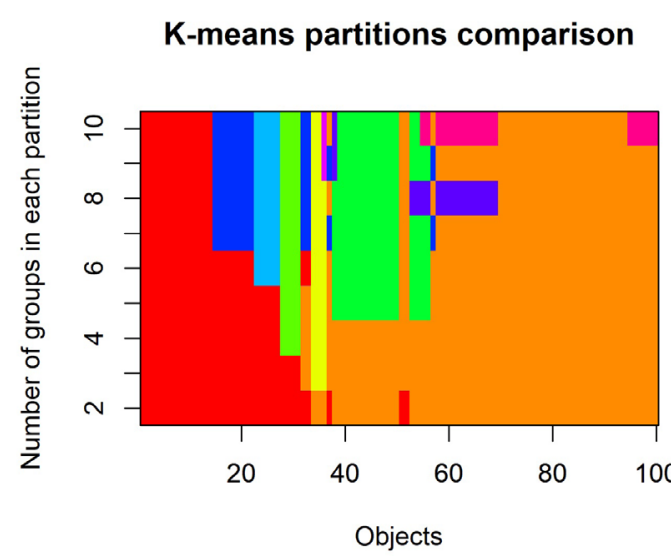

calinski

criterion

Figure 2. The Output of Calinski Method for the Running Dataset.

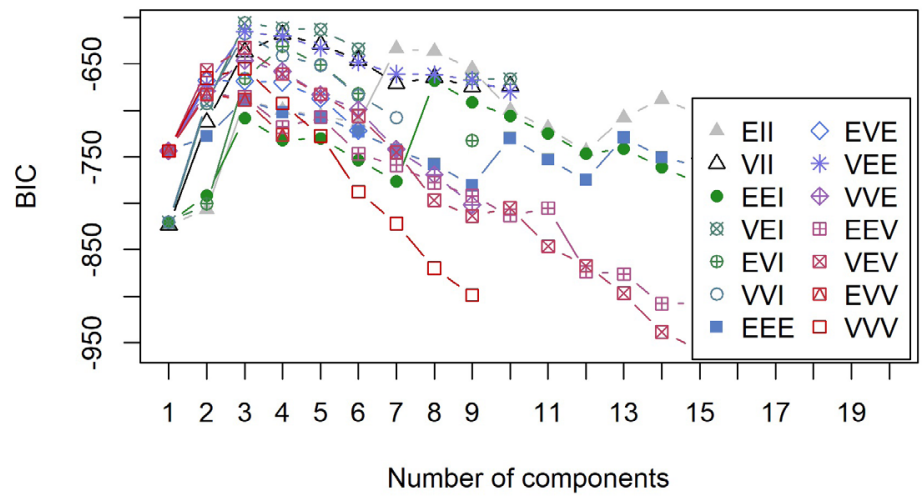

Figure 3. The Output of the Bayesian Approach for the Running Dataset.

the SPSS Clementine's implementation of K-means to cluster our dataset. For each cluster, the number of samples, its proximities from every other cluster, and the average value for each of the variables are presented in Table 1. According to Table 1, three clusters with 3, 31, and 66 samples were created. Since the number of samples in Cluster 1 was low and its proximities with the other two clusters were high, we inferred that these samples are outliers and could be removed. Hence, we had two clusters with 31 and 66 samples. Using the t-test, we realized that the turnover intention significantly differed in these two clusters $(P<0.001)$.

In the next step, we created the classification model for clusters 2 and 3 to predict the turnover intention in these clusters. We used the C\&R tree approach implemented in SPSS Clementine. Figure 4 shows the importance of each feature in making the decision tree in the mentioned clusters.

Figure 5 shows the clusters on the Radar chart type. In this figure, the second cluster is marked in red, and the third cluster in green. Because cluster 1 was a waste of data, it is not shown. 
Table 1. The Characteristics of the Output Clusters of K-means

\begin{tabular}{|c|c|c|c|c|c|c|}
\hline & $\begin{array}{l}\text { Number of } \\
\text { Samples }\end{array}$ & $\begin{array}{c}\text { Mean of } \\
\text { Interpersonal Conflict }\end{array}$ & $\begin{array}{c}\text { Mean of } \\
\text { Organizational Support }\end{array}$ & $\begin{array}{c}\text { Mean of } \\
\text { Work Overload }\end{array}$ & $\begin{array}{c}\text { Mean of } \\
\text { Work-Family Conflict }\end{array}$ & Proximities \\
\hline \multirow{2}{*}{ Cluster 1} & \multirow[b]{2}{*}{3} & \multirow{2}{*}{2.19} & \multirow{2}{*}{5.111} & \multirow{2}{*}{3.0619} & \multirow{2}{*}{3.044} & C3: 0.9486 \\
\hline & & & & & & C1: 1.1828 \\
\hline \multirow{2}{*}{ Cluster 2} & \multirow{2}{*}{31} & \multirow{2}{*}{5.313} & \multirow{2}{*}{2.731} & \multirow{2}{*}{5.097} & \multirow{2}{*}{5.499} & C3: 0.3542 \\
\hline & & & & & & C1: 1.1828 \\
\hline \multirow{2}{*}{ Cluster 3} & \multirow{2}{*}{66} & \multirow{2}{*}{4.342} & \multirow{2}{*}{2.48} & \multirow{2}{*}{4.758} & \multirow{2}{*}{4.484} & C2: 0.3542 \\
\hline & & & & & & C1: 0.9486 \\
\hline
\end{tabular}

\section{Discussion}

This study aimed to investigate the physicians' turnover intention in North Khorasan Province, which is one of the deprived areas of Iran. The average of the surveyed physicians' turnover intention was 5.47, which is above average and alarming. Research studies show that physicians in disadvantaged areas are more likely to migrate to developed cities and metropolitan areas. This can be attributed to better living conditions in big cities, opportunities for career development, ${ }^{35,36}$ and problems caused by cultural differences in small towns. ${ }^{37}$ Therefore, one of the most important concerns for HR managers in healthcare organizations is the maintenance of specialist physicians. The results of this study showed that the physicians' approach to turnover intention was divided into three clusters. The first cluster, which included perturbation data, was ignored in the analysis. Sixty percent of the physicians belonged to the second cluster. Moreover, women constituted 39\% of these clusters and

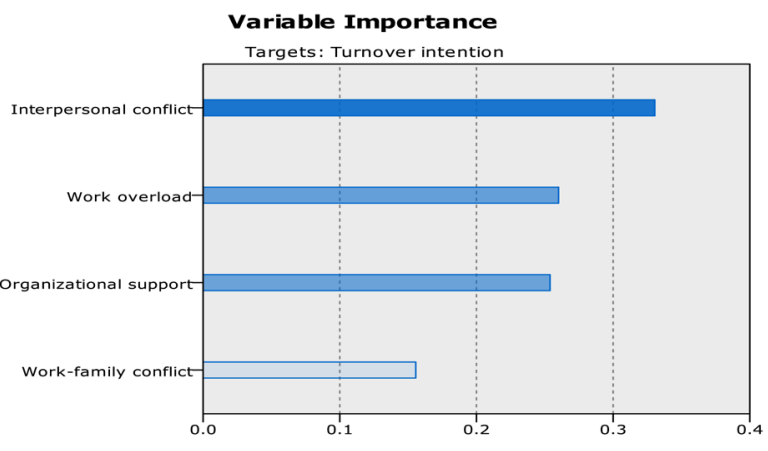

a) Cluster2

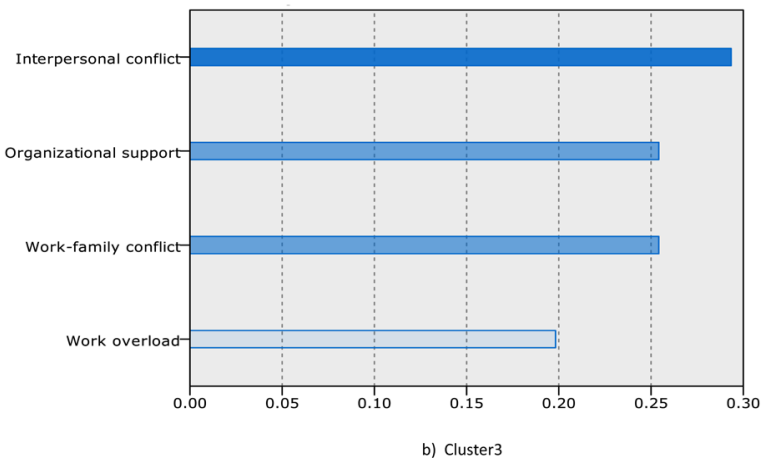

Figure 4. Feature Importance in the Classification. men $61 \%$, and the average physician experience was six years.

The turnover intention in this cluster was estimated to be very high, i.e. 6.2. Job overload, intrapersonal conflict, and work-family conflict in this cluster were higher than average and were estimated to be 5.50, 5.95, and 5.99, respectively. The perceived organizational support in this group was also estimated to be much lower than the average level of 2.73 .

Interpersonal conflict is the most important factor in this group of physicians' turnover intention (role ambiguity and role conflict). In the literature, role ambiguity and role conflict have been two predictors of employees' turnover intention.

Chang cited role ambiguity, role conflict, and workfamily conflict as role stressors and turnover intentions. ${ }^{38}$ De Clercq and Belausteguigoitia stated that the most important harmful effect of role ambiguity is turnover intention. They suggested that HR managers could reduce turnover intention by creating perceptions that organizational procedures are fair and by building trust in employees' relationships. ${ }^{39}$

Since the role ambiguity and role conflict in this study were the most important factors in the physicians' turnover intention, we returned to the field and asked several physicians to provide examples of factors that have led to conflict and role ambiguity. The results showed that perceived job conflict was in both task-related complications and relationship conflicts. In the field of

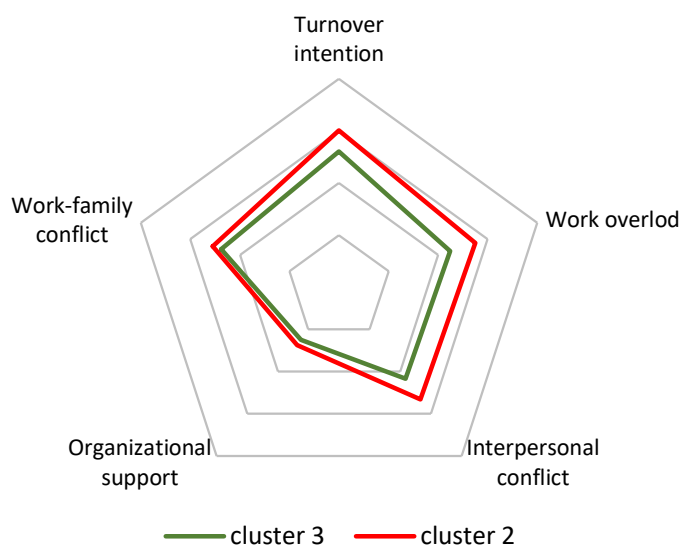

Figure 5. Clusters on Radar Chart Type. 
task-related conflicts, physicians were dissatisfied with workplace policies regarding the volume of educational and research work, lack of funding to provide specialized facilities, and lack of legal licenses to work in the office. In the field of relationship conflicts, one of the most important causes of job conflict was the cultural differences between physicians and local nurses and patients.

Some doctors said that the most important factor in creating a job conflict is an internal conversation about whether they did the right thing by coming to a smaller city for a better job. Research has also shown that $49 \%$ of job conflicts are caused by ego conflicts. ${ }^{39}$ Job overload and organizational support were the next most influential factors in this category, and ultimately the work-family conflict affected the physicians' turnover intention.

Wu et al also argued that the work-life conflict affects the physicians' turnover intention by the effect on job stress and job satisfaction. Also, physicians who work in rural and deprived areas perceived the work-family conflict more than physicians in urban and developed areas. ${ }^{35}$

The third cluster included $31 \%$ of the physicians. In this cluster, the number of females was higher than males, and $52 \%$ of the cluster were females and $48 \%$ were male. The average work experience of this cluster was less than that of the second cluster and equaled five years. Furthermore, the turnover intention in this cluster was estimated at $<2.5$.

In addition, physicians in this cluster experience more job overload, interpersonal conflict, and work-family conflict, and less organizational support for Cluster 2 . Since $>86 \%$ of specialist physicians were not indigenous, job conflict and cultural conflicts between physicians' and the medical staff and patients played a key role in the physicians' turnover intention. This was followed by the effect of organizational support on this group of physicians' turnover intention. Because this group of physicians had less work experience than the physicians in cluster 2 , they needed more organizational support to dedicate themselves

\section{Research Highlights}

\section{What Is Already Known?}

Deprived areas face a shortage of specialist physicians, and on the other hand, Organizational and psychological variables affect the nurses and physicians turnover intention and, managers can be useful in maintaining them by adopting appropriate strategies and actions

\section{What Does This Study Add?}

Two types of behavioral patterns were identified for the physicians' turnover intention in deprived areas, and in both of them, interpersonal conflict was an important predictive variable. Turnover intention predictions of physicians with more extended work experience are different from that of others and human resource managers must implement different strategies to keep physicians in deprived areas. to the new work conditions.

HR managers can improve the employees' perceptions of organizational support by performing the socialization process as the employees commence their work. ${ }^{40}$ For physicians in this category, the work-family conflict exerts a greater impact on the turnover intention than the physicians in cluster 2. Researchers identified workfamily conflict as an important potentially modifiable factor associated with elevated depressive symptoms in physicians, and this increase is greater for women. They believed that career attrition has the potential to reduce the negative consequences of work-family conflict. ${ }^{41}$

The last factor influencing turnover intention of this group of physicians is job overload. Studies suggest that organizational support predicts job overload. ${ }^{42,43}$ Because organizational support is highly important for this cluster of physicians, HR managers can reduce the job overload of these physicians by improving their perception of organizational support.

\section{Conclusion}

It seems that HR managers can play a determining role in reducing the turnover intention in deprived areas. They can improve physicians' perceptions of organizational support by work and time measurement and appropriate activities and creating a perception of the fairness of workload, while also reducing the job overload. HR managers can minimize the work-family conflict by implementing programs to support physician families as well as non-native physicians. Legislators and the government can apply both methods to protect these physicians, first, to provide financial support for these HR strategies, and second, to provide benefits such as the possibility of building offices in deprived areas for this group of physicians.

\section{Authors' Contributions}

$\mathrm{ZN}$ : performed the conception and design of the research performed, prepared tools and facilities for the field study and manuscript writing and revision; AS: conducted statistical analysis, drafted and participated in manuscript writing and revision.

\section{Conflict of Interest Disclosures}

The authors declare that they have no conflicts of interest.

\section{Ethical Approval}

This research was approved by the North Khorasan University of Medical Science with the code of 1398.60 .205 on May 13, 2019.

\section{References}

1. Hom PW, Griffeth RW. Structural equations modeling test of a turnover theory: cross-sectional and longitudinal analyses. J Appl Psychol. 1991;76(3):350-366. doi:10.1037/00219010.76.3.350.

2. Shaw JD, Duffy MK, Johnson JL, Lockhart DE. Turnover, social capital losses, and performance. Acad Manage J. 2005;48(4):594-606. doi:10.5465/amj.2005.17843940.

3. San Park J, Kim TH. Do types of organizational culture matter in nurse job satisfaction and turnover 
intention? Leadersh Health Serv. 2009;22(1):20-38. doi:10.1108/17511870910928001.

4. Badri SK. Affective well-being in the higher education sector: connecting work-life balance with mental health, job satisfaction and turnover intention issues inside the academia setting. Int J Happiness Dev. 2019;5(3):225-241. doi:10.1504/ijhd.2019.103382.

5. Fukui S, Wu W, Salyers MP. Mediational paths from supervisor support to turnover intention and actual turnover among community mental health providers. Psychiatr Rehabil J. 2019;42(4):350-357. doi:10.1037/prj0000362.

6. Howard WG, Donofrio HH, Boles JS. Inter-domain work-family, family-work conflict and police work satisfaction. Policing: An International Journal of Police Strategies \& Management. 2004;27(3):380-395. doi:10.1108/13639510410553121.

7. Rezaee R, Shoaahaghighi P, Bordbar N, Tavani K, Ravangard R. Factors affecting the family physicians' intention to leave the job: a case of Iran. Open Public Health J. 2019;12(1):482488. doi:10.2174/1874944501912010482.

8. Kinnunen U, Mauno S. Antecedents and outcomes of work-family conflict among employed women and men in Finland. Hum Relat. 1998;51(2):157-177. doi:10.1177/001872679805100203.

9. Rahimi H, Kasaee A, Asadpour E. Investigating the role of job engagement and job self-efficacy with job-family conflict in female nurses of Tehran. Avicenna J Nurs Midwifery Care. 2019;26(6):366-376. doi:10.30699/sjhnmf.26.6.366.

10. Lu Y, Hu XM, Huang XL, et al. The relationship between job satisfaction, work stress, work-family conflict, and turnover intention among physicians in Guangdong, China: a crosssectional study. BMJ Open. 2017;7(5):e014894. doi:10.1136/ bmjopen-2016-014894.

11. Anafarta N. The relationship between work-family conflict and job satisfaction: a structural equation modeling (SEM) approach. Int J Bus Manag. 2011;6(4):168-177. doi:10.5539/ ijbm.v6n4p168.

12. Macpherson C. Difficulties for a practitioner preparing a family for the death of a parent: a narrative inquiry. Mortality. 2018;23(3):247-260. doi:10.1080/13576275.2017. 1339677.

13. Vazirani S, Hays RD, Shapiro MF, Cowan M. Effect of a multidisciplinary intervention on communication and collaboration among physicians and nurses. Am J Crit Care. 2005;14(1):71-77. doi:10.4037/ajcc2005.14.1.71.

14. Brown SP, Peterson RA. Antecedents and consequences of salesperson job satisfaction: meta-analysis and assessment of causal effects. J Mark Res. 1993;30(1):63-77. doi: $10.2307 / 3172514$.

15. Baruch GK, Barnett R. Role quality, multiple role involvement, and psychological well-being in midlife women. J Pers Soc Psychol. 1986;51(3):578-585. doi:10.1037/00223514.51.3.578.

16. Ebbers JJ, Wijnberg NM. Betwixt and between: role conflict, role ambiguity and role definition in project-based dualleadership structures. Hum Relat. 2017;70(11):1342-1365. doi:10.1177/0018726717692852.

17. Baranik L, Roling EA, Eby LT. Why does mentoring work? the role of perceived organizational support. J Vocat Behav. 2010;76(3):366-373. doi:10.1016/j.jvb.2009.07.004.

18. Arvan ML, Dreibelbis RC, Spector PE. Customer service stress: a meta-analysis of customer mistreatment. In: Perrewé
PL, Harms PD, eds. Examining the Role of Well-being in the Marketing Discipline (Research in Occupational Stress and Well Being). Vol 17. Bingley: Emerald Publishing Limited; 2019:117-136. doi:10.1108/s1479-355520190000017006.

19. Eisenberger R, Huntington R, Hutchison S, Sowa D. Perceived organizational support. J Appl Psychol. 1986;71(3):500-507. doi: 10.1037/0021-9010.71.3.500.

20. Ahmad A. Work-family conflict among junior physicians: Its mediating role in the relationship between role overload and emotional exhaustion. J Soc Sci. 2010;6(2):265-271. doi:10.3844/jssp.2010.265.271.

21. Nikkhah-Farkhani Z, Piotrowski A. Nurses' turnover intention a comparative study between Iran and Poland. Med Pr. 2020;71(4):413-420. doi:10.13075/mp.5893.00950.

22. Rizzo JR, House RJ, Lirtzman SI. Role conflict and ambiguity in complex organizations. Adm Sci Q. 1970;15(2):150-163. doi: $10.2307 / 2391486$.

23. Yoon J, Thye SR. A dual process model of organizational commitment: Job satisfaction and organizational support. Work Occup. 2002;29(1):97-124. doi:10.1177/07308884020 29001005

24. Altaf A, Awan MA. Moderating affect of workplace spirituality on the relationship of job overload and job satisfaction. J Bus Ethics. 2011;104(1):93-99. doi:10.1007/ s10551-011-0891-0.

25. Netemeyer RG, Brashear-Alejandro T, Boles JS. A crossnational model of job-related outcomes of work role and family role variables: a retail sales context. J Acad Mark Sci. 2004;32(1):49-60. doi:10.1177/0092070303259128.

26. Pirhayati S, Neisi A, Naami A. The relationship between work family conflict with job engagement, and intention to stay on job in employees of one petrochemical company in Mahshahr. J Soc Psychol. 2012;7(23):95-114. [Persian].

27. Beshlideh K, Neisi A, Chach M. A study of personality traits and organizational variables as predictors of accident-involvement in two groups of accident-involved and accident-free bus drivers in Tehran city. Journal of Psychological Achievements. 2010;17(1):69-88. [Persian].

28. Hashemi T, Golparvar M. The role of perceived organizational support on relationship between job stress and emotional exhaustion with turnover among nurses. J Clin Nurs Midwifery. 2016;4(4):29-39. [Persian].

29. Mokarami H, Choobineh A, Nazifi M. A systematic review on the available questionnaires for the assessment of workrelated stressors. Iran Occup Health. 2017;14(5):62-74. [Persian].

30. Cortina JM. What is coefficient alpha? an examination of theory and applications. J Appl Psychol. 1993;78(1):98-104. doi:10.1037/0021-9010.78.1.98.

31. Lawshe $\mathrm{CH}$. A quantitative approach to content validity. Pers Psychol. 1975;28(4):563-575. doi:10.1111/j.1744-6570.1975. tb01393.x.

32. Lawler E, Cammann C, Nadler D, Jenkins D. Michigan Organizational Assessment Questionnaire. APA PsycTests; 1975. doi:10.1037/t01581-000

33. Lloyd S. Least squares quantization in PCM. IEEE Trans Inf Theory. 1982;28(2):129-137. doi:10.1109/tit.1982.1056489.

34. Breiman L, Friedman J, Olshen R, Stone C. Classification and Regression Trees. Boca Raton, Florida: CRC Press; 1984.

35. Wu X, Kumar V, Ross Quinlan J, et al. Top 10 algorithms in data mining. Knowl Inf Syst. 2008;14(1):1-37. doi:10.1007/ s10115-007-0114-2. 
36. Wen T, Zhang Y, Wang X, Tang G. Factors influencing turnover intention among primary care doctors: a crosssectional study in Chongqing, China. Hum Resour Health. 2018;16(1):10. doi:10.1186/s12960-018-0274-z.

37. Lu Y, Hu XM, Huang XL, et al. Job satisfaction and associated factors among healthcare staff: a cross-sectional study in Guangdong province, China. BMJ Open. 2016;6(7):e011388. doi:10.1136/bmjopen-2016-011388.

38. Chang S-I. Work rolestressors and turnover intentions: astudy of IT personnel in South Korea. Ger J Hum Resour Manag. 2008;22(3):272-290. doi:10.1177/239700220802200304.

39. De Clercq D, Belausteguigoitia I. Reducing the harmful effect of role ambiguity on turnover intentions. Pers Rev. 2017;46(6):1046-1069. doi:10.1108/pr-08-2015-0221.

40. CCP Global. Workplace conflict and how businesses can harness it to thrive (Report). Available from: http:// www.pablolinzoain.com/workplace-conflict-and-howbusinesses-can-harness-it-to-thrive/.

41. Perrot S, Bauer TN, Abonneau D, Campoy E, Erdogan B, Liden RC. Organizational socialization tactics and newcomer adjustment:the moderating role of perceived organizational support. Group Organ Manag. 2014;39(3):247-273 doi:10.1177/1059601114535469.

42. Efeoğlu IE, Ozcan S. Work-family conflict and its association with job performance and family satisfaction among physicians. Aust J Basic Appl Sci. 2013;7(7):43-48.

43. Foley S, Hang-Yue N, Lui S. The effects of work stressors, perceived organizational support, and gender on workfamily conflict in Hong Kong. Asia Pac J Manag. 2005;22(3):237-256. doi:10.1007/s10490-005-3568-3. 